\title{
Sons, Ritual e História Indígena no Oeste do Chaco
}

\author{
María Eugenia Domínguez \\ Universidade Federal de Santa Catarina, Florianópolis, Santa Catarina, Brasil \\ E-mail: eugison@yahoo.com
}




\section{Resumo}

Focando no plano sonoro da ação ritual, o texto descreve a festa arete guasu que os chané e guarani do Chaco argentino, boliviano e paraguaio realizam anualmente. A repetição e a redundância na produção sonora do rito, tanto quanto as variações, constituem a sua musicalidade. Por sua vez, a repetição conjuga-se com as diferenças entre os temas que pautam a sequência do ritual. Aqui se reflete sobre a relação desses planos formais com o tempo ritual e o tempo histórico.

Palavras-chave: Chané. Guarani. Chaco. Argentina. Bolívia. Paraguai.

\section{Abstract}

Focusing on the sonic dimenson of ritual action, this text describes some performances of the arete guasu held annually by chane and guarani people in the Argentine, Bolivian and Paraguayan Chaco. Repetitiveness and redundancy of sound as well as variations are key in this rite's musicality. Anyway, repetition is counterbalanced with differences among different themes that structure the ritual's sequence. Here we describe the relationship of these formal aspects with ritual and historical temporalities.

Keywords: Chané. Guarani. Chaco. Argentina. Bolívia. Paraguai. 


\section{Apresentação}

Em primeiro lugar existe a noção de repetição. Toda vez que pensamos a respeito da medida do tempo, preocupamo-nos com algum tipo de metrônomo; pode ser o tique-taque de um relógio, ou uma pulsação, ou a recorrência a dias, luas, estações anuais- mas há sempre alguma coisa que se repete.

Em segundo lugar existe a noção de não repetição. Estamos cientes de que todas as coisas vivas nascem, crescem e morrem, e que este

processo é irreversivel.

(Dois ensaios a respeito da representação simbólica do tempo, Edmund Leach)

Dode-se argumentar que o arete guasu, uma das festas indígenas mais 1 conhecidas no oeste do Chaco, é um ritual musical, na medida em que o som de flautas e de tambores é indispensável para que esse ritual aconteça. A festa é celebrada tanto no sudeste da Bolívia quanto no oeste do Paraguai e no oeste do Chaco argentino na maioria das comunidades chané e guarani da região. Os chané são descendentes de populações do tronco liguístico aruak que habitaram a região desde antes da chegada de população guarani (Combès, 2005; 2007). O termo guarani nessa área engloba os que a literatura deu a conhecer como chiriguano (embora eles prefiram não usar esse etnônimo, pois alguns usam ava, outros apenas guarani), os simba, isoseños e tapiete. No Paraguai, os guarani do oeste são referidos muitas vezes como guarayos pelos não indígenas; eles utilizam maiormente o etnônimo guarani para se referirem a si mesmos, embora nos censos sejam nomeados como "guarani occidental", para distingui-los dos guarani nhandeva, que também habitam o Chaco, e dos guarani do leste do país (mbyá, aché, avá e paĩ-taviterã). 
No arete guasu, as pessoas se reúnem para dançar e partilhar bebidas durante alguns dias, visitam parentes e as casas de pessoas da própria comunidade ou de comunidades vizinhas, dando, assim, continuidade à antiga tradição chiriguano e chané do convite (Giannecchini, 1996; Susnik, 1968; Sánchez, 1998; Villar, 2011). Algumas pessoas afirmam que, na época do arete, também os antepassados mortos vêm para dançar com os vivos. Para alguns ipaye ${ }^{l}$, outros seres e não apenas os $a \tilde{n} a^{2}$ também se aproximam em ocasião da festa e podem ser vistos, ouvidos ou cheirados entre as pessoas dançando. Seja como for, uma coisa é certa: no arete tudo mundo se reúne para partilhar bebidas e dançar, e só se dança se houver música.

A festa é realizada nos meses de verão, entre o mês de janeiro e a páscoa, e é exclusivamente nesse período que a música de flautas e de tambores é ouvida. Na etnologia chaquenha, a literatura que se refere ao arete é farta, sobretudo no que diz respeito aos significados dos elementos que o integram e às relações com as cosmologias chané e guarani. A ideia aqui é complementar as descrições existentes, focando agora no plano sonoro da ação ritual. As observações que comparo surgem das festas em que participei em diferentes comunidades na área compreendida entre Tartagal e Pocitos na Argentina durante cinco anos consecutivos (2014 a 2018); dos desfiles de carnaval nas cidades próximas das comunidades onde estas participam com seus conjuntos de músicos (em Aguaray e Tartagal); o festival Arete Guazu em Aguayrenda na Bolívia (fevereiro de 2015), e o arete guasu de Santa Teresita e Macharetí no Chaco paraguaio durante três anos consecutivos $(2016 \text { a } 2018)^{3}$.

O conjunto musical do arete é composto de uma flauta, caixas e tambores em números variáveis, todos executados exclusivamente por homens. Participei da festa durante cinco verões consecutivos em diferentes localidades da Argentina, Bolívia e Paraguai, e somente em uma única oportunidade vi uma mulher tocando caixa entre os músicos do arete. As flautas são de dois tipos (temïmbi [quena] e pinguyo), ambas longitudinais e sempre executadas por um solista. Os flauteros alternamse para tocar, o toque de um nunca se dá de forma simultânea ao de um outro. Os cajeros são no mínimo três, embora em alguns casos 
um grande número de caixas se junta ao som sempre individual do temïmbï ou do pinguyo ${ }^{4}$.

Na frente ou em volta dos músicos, rodas de mulheres, homens e mascarados - a quem as pessoas se referem como "aña-aña", "máscaras", "mascaritas" ou "aguëro-agüero" - dançam em círculos. Geralmente há crianças na festa, elas também dançam, em alguns casos formam rodas exclusivamente de crianças. Se tomados das mãos os participantes dançam em roda; se abraçados de a dois ou a três avançam em filas que giram em torno de um eixo, da mesma forma que as aspas de um moinho. Repete-se sempre o mesmo passo, sendo que a roda muda a direção do giro quando a flauta o indica. Muitas pessoas ficam sentadas ou em pé nos contornos do pátio, praça ou local onde a festa ocorre, bebendo, conversando, ou apenas observando a cena: os dançarinos são o foco dos olhares.

Embora seja por meio de várias linguagens que o arete torna-se a experiência multisensorial que é - em que sons, cheiros, movimentos e os aspectos visuais de máscaras e roupas compõem conjuntamente a textura do ritual - o objetivo aqui é dar atenção especial aos aspectos sonoros da festa. Na época do arete podem se dar situações em que, embora faltem os mascarados ou as pessoas dispostas para dançar, haja sim um conjunto de homens tocando instrumentos. Em parte, essa é a razão que me leva a sublinhar, de início, que o arete é um ritual musical. Não que a música seja mais importante do que as outras linguagens quando elas se dão de forma combinada, mas, diferente das outras, ela é indispensável. Os mitos associados ao arete também podem não ser conhecidos pela maioria dos que participam do encontro e as máscaras podem não estar presentes, mas enquanto houver música a festa está garantida. Isso, vale a ressalva, sempre e quando haja trago ${ }^{5}$ : sem bebida os instrumentos não soam.

Como em muitas outras festas e rituais sul-americanos, seja nos Andes ou nas terras baixas, a associação entre música e álcool é aqui estreita (Abercrombie, 1993; Beaudet, 1997; Martínez, 2002; 2014). Por mais que, durante a festa, todo mundo beba, os músicos são servidos com atenção redobrada. Geralmente tem um recipiente com bebida aos pés dos músicos para que eles possam beber à vontade. Seja um pote de 
cerâmica ou plástico com chicha, uma jarra grande com vinho, ou um balde cheio de latas de cerveja, os músicos incondicionalmente terão bebida. Os músicos precisam beber para tocar, e, quando um flautero não consegue tirar um bom som da flauta, sem demora os presentes advertirão jocosamente "está seco" ou "falta trago". Os músicos geralmente explicam o hábito de beber para tocar como uma forma de evitar a "vergüenza", e não raro se recusarão a tocar estando "sanos" (sóbrios). Alguns trabalhos etnográficos que consideram esse aspecto examinam o vínculo entre a produção sonora e o consumo de álcool, mostrando que, para além de descrições que remetem a embriaguez ao patológico ou ao escapismo, pode-se identificar dimensões produtivas do beber coletivamente entre os indígenas sul-americanos, já que o consumo de álcool muitas vezes oportuniza a comunicação com o invisível, a crítica social e com o desafio ao poder (Saignes, 1993 apud Martínez, 2002, p. 3). No caso sob estudo, as formas de beber que acompanham a performance musical permitem observar alguns aspectos da socialidade ali pautada. Porque não apenas os flauteros precisam se hidratar com trago (bebida), mas as flautas também o fazem. Seja antes de começar a tocar quanto de tempo em tempo durante uma execução que pode durar algumas horas, os flauteros enchem a boca com um gole de bebida e com força assopram o líquido pra dentro do tubo da flauta. A explicação que ouvi dos músicos é a de que a flauta seca não soa - fato que qualquer flautista reconhece - e que é por meio da flauta que "os donos" pedem bebida, o que não contradiz o primeiro argumento. Nesse sentido, a realidade chaquenha aproxima-se da de outras sociedades indígenas sul-americanas tanto andinas quanto amazónicas - na quais as flautas e seu som agenciam potências não humanas (Brabec de Mori; Seeger, 2013). É preciso levar em consideração que as habilidades necessárias para incorporar e executar temas tocados pelos outros, para criar novos temas e "preparar" bons instrumentos, está estreitamente relacionada ao domínio das relações com os "donos" e com outras entidades das cosmologias chané e guarani. E as relações que os flauteros - que em muitos casos são ipaye - mantêm com tais entidades estão baseadas na reciprocidade, envolvendo, entre outras coisas, a bebida. Aliás, 
todas as pessoas que participam, de um modo ou outro, da festa, compartilham a bebida e, como bem frisou uma vez um homem chané ao conversarmos sobre o arete, "na festa reúnem-se e bebem juntas pessoas que jamais estariam juntas numa outra situação". Assim, a bebida parece dissolver temporariamente certas tensões e as distâncias sociais e cosmológicas que vigoram em outros momentos são colocadas em suspenso no tempo do ritual.

Portanto, na atualização do arete, músicos e trago são, sem dúvida, os elementos necessários para que os outros possam estar presentes. Isso pode ser interpretado de duas formas: por um lado, fala de uma espécie de hierarquia estrutural, em que as diferentes linguagens que compõem o rito têm níveis desiguais de dispensabilidade. Por outro lado, poderia-se dizer que, no processo histórico de "dissolução" do complexo simbólico do arete, durante o último século, a música e a embriaguez, que caracterizam a festa, são "o que restou". Embora essas hipóteses não sejam mutuamente excludentes, referir-me-ei a alguns possíveis desdobramentos da primeira delas, descrevendo parte da musicalidade que dá vida ao arete. Por meio do conceito de musicalidade (Piedade, 2013), a proposta é referir-se ao conhecimento musicalcultural partilhado por diferentes grupos da região como conhecimento constituído por um conjunto de elementos musicais e significações associadas. Para além de possíveis processos de "dissolução" das culturas indígenas da região, a musicalidade do arete e tudo o que ela atualiza, continua a definir a paisagem do oeste do Chaco.

\section{A Literatura, a História e a Musicalidade Indígena}

O pessimismo sentimental, como diria Marshall Sahlins (1997), é uma marca registrada na antropologia sobre o Chaco. Na literatura etnológica mais clássica, as passagens que se referem à decadência da música (ou da cultura) indígena são eloquentes:

Es también en estas fiestas donde uno escucha y ve lo que queda de la antigua cultura de estos índios. (Nordenskiöld, 2002, p. 216) 
Se puede concluir asi que la cultura chiriguano-chané está en proceso de desaparición, o mejor dicho de disolución. (Rocca, 1973, p. 755)

Sobre la región del Chaco occidental [...] se cierra para nosotros el telón de la noche. (Magrassi, 1981, p. 55)

Ninguém negaria que nos últimos cem anos muitas coisas mudaram - para bem ou para mal - na vida dos indígenas do Chaco. As forças modernizadoras tiveram e continuam a ter um impacto tremendo na vida dos indígenas da região. Porém, o pessimismo exagerado não deveria nos impedir de enxergar algumas continuidades culturais importantes. As transformações em todas as ordens da vida chané e guarani são tantas, tão profundas e variadas que seria difícil reduzi-las em bloco na metáfora da dissolução.

Algumas fontes evidenciam que antigamente o arete acontecia mais adiante no nosso calendário anual - mais ou menos ao final do mês de maio, associado ao momento de aparição das plêiades ${ }^{6}$ (Giannecchini, 1996; Sánchez, 1998). No oeste do Chaco tem desde o século XVIII uma presença missionária cristã bastante marcante ${ }^{7}$, ao ponto de que muitas das comunidades atuais são ex-missões. A presença católica na região trouxe com ela, entre outras coisas, um calendário cristão, alterando, em consequência, a temporalidade do arete que atualmente associa-se ao carnaval. Como em outros carnavais, o período de permissividade clausura-se com a quaresma, antes da pascoa. Todavia, e apesar dessa associação ao calendário cristão e ao carnaval, as explicações dos protagonistas sobre os significados da festa, o seu surgimento e o que a desencadeia remetem ao universo mitológico indígena. Embora coexistam diferentes mitos entre os chané e guarani da região que podem ser ouvidos ao se perguntar sobre o assunto, muitos deles remetem ao corpus mítico tradicional e não cristão. Dependendo dos casos ouve-se falar da raposa que, quando se aproxima o carnaval, vem tocando flauta e caixa trazendo a música; do rato e da raposa que, imitando o som do assobio do focinho do primeiro e o chocalhar da mandíbula da segunda, criam a música de flautas e caixas respetivamente e a ensinam aos humanos por meio do sonho para que possam ter a sua festa; ou bem dos dois rapazes que, 
expulsos da comunidade após uma briga, criam a música do arete na sua reclusão no mato: ao ouvir esse som, as pessoas da aldeia chamam eles de volta para que tragam a música com eles, oportunizando a festa. Também ouvi que os aña, os que vêm do matyvirocho ${ }^{8}$ ano atrás de ano, de lá trazem os sons e os entregam aos músicos das comunidades para que a celebração aconteça. E, junto com eles, se vai a música no fim da festa ${ }^{9}$. Em todos os casos há uma associação entre a música e o mato (monte, kaa), os animais, os aña e outros não humanos como os donos ou a salamanca. Pode se pensar que esses outros são, de alguma maneira, musicalizados (Hill, 2014) e, nesse processo, reconhecidos. Aqui o som é a relação que faz possível esse coexistir, esse uso partilhado do tempo-espaço ritual. Desse modo, a presença da música do arete nas comunidades chaquenhas, ao instalar um tempo - o tempo do rito que evoca essa associação durante o período que dura ${ }^{10}$, atualiza uma série de mitos que referem a ela.

Apesar de saber que a cosmovisão que antigamente dava sentido ao arete misturou-se com muitos elementos que poderiam ser considerados inovações, a centralidade da música - dentre as linguagens que integram o rito - e dos músicos - dentre as pessoas que participam do rito - não parece ter sido opacada pela história chaquenha. Embora os músicos mais velhos, muitas vezes, sejam pessimistas em relação ao futuro da sua arte, temendo que ela morra com eles, os espaços para a execução da música do arete se multiplicam, os jovens aprendem a tocar e preparam instrumentos, matérias-primas industriais são adaptadas para ajustá-las aos padrões conhecidos na fabricação e na execução dos instrumentos e as inovações nos repertórios são arranjadas de modo que respeitem a estrutura ritual tradicional (Domínguez, 2016). Não parece exagerado afirmar que as mudanças e as variações são, em linhas gerais, conservadoras.

Para além das transformações de todo tipo, o arete e a tradição do convite, com a circulação espacial de pessoas e de coisas que estabelecem, continuam tanto quanto antigamente a definir o oeste do Chaco como lugar, pautando-lhe, nesse mesmo movimento, uma temporalidade. E se falo aqui de continuidade é porque o fenômeno já era assim descrito nas crônicas do século XIX: 
En solemnes banquetes transcurren los meses de mayo a agosto, más aún cuando hay abundancia de maiz, de pueblo en pueblo, de una región a otra. Y esto no impide que en cada pueblo se celebren banquetes particulares entre conocidos y familiares [...]. (Giannecchini [1898] 1996, p. 341)

$\mathrm{O}$ arete agrega às comunidades que o celebram em uma rede que serve de esqueleto para o que se pode imaginar como uma espécie de área cultural na região chaquenha da Bolívia, Argentina e Paraguai (Villar; Combès, 2012). As linhas que unem os diferentes parajes são caminhos pelos quais, individual ou coletivamente, as pessoas chané e guarani já transitaram. Na época do arete ativa-se toda uma série de deslocamentos em diferentes níveis: de gente que viaja desde outras localidades para participar da festa na sua comunidade com seus parentes, de cajeros e flauteros que circulam pelas festas de diferentes parajes, e de grupos de pessoas que circulam para dançar por diferentes casas da mesma comunidade enquanto dura a festa.

As festas dos chiriguano sempre chamaram a atenção daqueles que visitaram o Chaco. Para os olhos e os ouvidos europeus do século XIX, o panorama que as festas indígenas ofereciam nunca foi muito agradável. Nos escritos dos religiosos que missionaram na região, as referências às festas associadas à tradição chiriguana do convite destacam o "barulho" que os indígenas produziam (Sánchez, 1998). Já nos relatos do pesquisador Erland Nordenskiöld, que viajou ao país dos chané e dos chiriguano na década de 1910, o que mais parece chamar a sua atenção é o fato de que nessas festas as pessoas podem dançar durante dias e dias - com as suas noites ai incluídas - ao som "das mesmas melodias"; em um ambiente saturado de sons tristes e saudosos, de berros e de choros:

Entre los chané del valle de Itiyuro he observado a los indios bailar en una fiesta de cangüí. Algunos de los ancianos estaban de pie alrededor de un yumbuy con cangüí, en grupos de a dos cantando una canción monótona y marcando el compás con los pies. (Nordenskiöld, 2002, p. 221)

Oscurece y la fiesta se hace más agitada. Se cantan canciones monótonas y melancólicas que suenan lúgubres a través de la oscuridad de la noche, se chilla y se llora. Nos 
vamos sintiendo incómodos entre tanta gente borracha que no nos deja dormir. (Nordenskiöld, 2001, p. 24)

$\mathrm{Na}$ verdade, grande parte da literatura etnológica do Chaco remarca que a música dos índios é monótona e repetitiva. A minha intenção aqui é complementar essa literatura, dialogando agora com a antropologia mais recente para analisar as relações entre sons, rito e história indígena. Dando centralidade ao plano sonoro da ação ritual, buscarei pensar a repetição no seu lado produtivo, particularmente em relação à temporalidade que ela instala. Por sua vez, descrevo a repetição na sua articulação com seu oposto, a diferença, presente tanto nas variações quanto na organização sequencial do repertorio do arete chané e guarani.

\section{Repetições e Sequências}

O carácter repetitivo geralmente atribuído às musicalidades chaquenhas não seria necessariamente um problema se não fosse pelo fato de ele ser muitas vezes considerado índice da sua baixa qualidade estética $^{11}$. Mas, se a gente se despir de juízos de valores como esse, pode ser interessante aceitar que a música do arete é repetitiva sim, mas que isso, longe de ser um problema, é uma das suas virtudes, na medida em que contribui com a sua potência sonora. Os critérios que predominam entre os protagonistas do arete ao avaliar a qualidade estética da execução de um flautero concentram-se na eficácia do seu toque, seja para fazer com que muitas pessoas dancem ou no sentido de evocar determinadas memórias e afetos. Essa eficácia está, portanto, associada a padrões formais reconhecidos pelos participantes da festa. Como me contou um homem chané de Campo Durán (no oeste do Chaco argentino), na fase final do arete de 2017, um menino flautero, acompanhado de alguns cajeros, entrou na arena ritual tocando temïmbï. Todos ficaram bastante perplexos, pois não é usual que uma criança toque flauta nessa instância formal de realização da festa. "Porém, as velhinhas choraram quando ouviram ele tocar, a sua flauta trazia sim melodias antigas", explicou ele, revelando que as emoções às quais apela esteticamente a música do arete estão longe daquelas que a tradição musical ocidental identifica com o virtuosismo ou a beleza. 
Apesar do fato de as flautas que um e outro flautero fabrica artesanalmente não emitirem necessariamente os mesmos tons e de que cada flautero toca do seu jeito - e a enorme variabilidade entre os estilos individuais é facilmente reconhecida e muito valorizada por todos - a música do arete apresenta características relativamente estáveis tanto no plano estrutural quanto estilístico. Pode-se afirmar, sem dúvida, que a música do arete é um mesmo gênero musical que singulariza a paisagem sonora da região. Nenhum dos interlocutores indígenas com quem dividi gravações realizadas em comunidades distantes no espaço da geografia chaquenhas, comunidades entre as que existem diferenças tanto étnicas quanto linguísticas, questionou o fato de a música de uns e de outros ser a mesma.

Além de ser interpretada com instrumentos do mesmo tipo nas diferentes comunidades, em quase todas as manifestações apresenta estruturas em que a repetição de frases breves e suas variações caracterizam o estilo sonoro. Embora as variações de distinto tipo sejam frequentes, dentre elas predominam as repetições na estruturação das frases melódicas da flauta. Os motivos repetidos podem ser parte da melodia ou a melodia completa. Nos casos em que as melodias estruturam-se com base em progressões ascendentes ou descendentes, a repetição também aparece como um princípio estruturante central, embora se trate nesses casos da repetição de determinadas passagens melódicas - motivo principal ou modelo - que serão reproduzidas em diferentes alturas. Essas características possibilitam, por sua vez, que temas da música popular possam ser ajustados e interpretados no estilo da música do arete, como no caso do huayno de Los Kjarkas, "Wayayay"12.

Por mais que os músicos afirmem que todos os instrumentos musicais do arete são igualmente importantes, observa-se um destaque para a flauta no que diz respeito à condução do conjunto. Sendo o único solista, é o flautero quem rege o andamento dos diferentes momentos de um tema e indica o final desses momentos. Embora formalmente o acompanhamento é sempre o mesmo, podem se dar diferenças no andamento da música nos distintos momentos da festa. A diferença no andamento dos toques das diferentes comunidades, por sua vez, 
é o critério que meus interlocutores destacam na hora de apontar as diferenças de estilo que existem entre os toques de uns e outros.

Durante os dias do arete, as pessoas dançam em rodas que giram em círculos durante horas a fio, realizando sempre um mesmo passo que é interrompido apenas para mudar a direção em que a roda gira. O passo da dança também se estrutura em um paralelismo simétrico, onde pé direito e esquerdo se alternam de forma regular. No som que os passos produzem, ao friccionar a terra seca do chão, reverbera a estrutura simétrica dos movimentos. Todos esses elementos ajudam a compor tanto a paisagem sonora da época do arete quanto a experiência sinestésica do ritual. ${ }^{13}$

No arete não se canta, mas há um tipo de emissão vocal - o sapukai que marca presença de forma ubíqua, sendo mais um traço característico do ambiente sonoro da festa. O termo sapukai pode ser traduzido como grito, mas, nesse caso, não se trata de um grito qualquer. O sapukai é um tipo de emissão da voz potente e agudo que tanto homens quanto mulheres podem fazer em momentos de muita emoção. Seu som é tanto descritivo quanto performativo, em se tratando de uma manifestação de euforia do emissor que contagia os que ao escutá-la a reproduzem. Assim, a paisagem sonora do arete é saturada pelo som de sucessivos sapukai que deixam a impressão de estarem ecoando entre si.

Embora exista muita variabilidade nas formas que pode adotar um sapukai, é possível reconhecer um padrão formal que se repete com frequência. Há aqui também uma estrutura simétrica (duas metades idênticas em termos de duração absoluta, mas que apresentam diferentes subdivisões), que cada emissor pode repetir três ou quatro vezes. Se ajustando a uma forma modelar que se repete e reverberando na paisagem sonora do arete, o sapukai induz a euforia que caracteriza muitos dos momentos da festa. Seu significado, ou melhor, a sua eficácia fundamenta-se na forma e não na remissão a algum conteúdo de tipo verbal ou semântico. O significado do sapukai assenta-se justamente na redundância da sua configuração formal. Como em outros rituais, aqui, a configuração formal das múltiplas linguagens que compõem o ambiente caracteriza-se pela redundância, convencionalidade e pela fusão de linguagens ${ }^{14}$. 
O sapukai, ao se juntar aos outros sons do arete, induz um tipo de experiência particular e um tipo de temporalidade destacada do fluxo ordinário do tempo linear. Se o tempo linear é uma sucessão de diferenças, as repetições sucessivas aproximam as pessoas de um "tempo sem seta"15. Da forma em que o interpreto, o arete, como todo ritual, introduz um corte transversal no fluxo ordinário do tempo, oportunizando uma experiência temporal marcada pela permanência. Por meio da repetição na sintaxe das diferentes linguagens que compõem o rito, o tempo do arete adquire uma densidade distinta onde tudo se repete e retorna, e é como se o tempo se estancasse.

Afirmar que os sons do arete são repetitivos não é dizer que a música é toda igual. De fato, o repertório do arete é uma sequência de temas distintos que pautam a estrutura do ritual, marcam seus diferentes momentos e prescrevem determinados movimentos e emoções que se associam a essas diferentes etapas ${ }^{16}$. Na parte final do arete, por exemplo, quando o tigre e o touro se enfrentam em combate, o andamento é bem mais lento (em torno de $60 \mathrm{bpm}$ ) do que nos momentos em que se toca para que as pessoas dancem (geralmente acima de $120 \mathrm{bpm}$ ). No Paraguai, quando o touro e o tigre entram na arena ritual para lutar, os músicos afrouxam as amarrações dos couros do bumbo e das caixas, obtendo, assim, um som grave e abafado que dá um caráter mais sério a esse momento. O som grave contrasta com o som limpo e ligeiro dos momentos de dança mais agitada e eufórica. Na sequência de temas do arete, esse adágio marca um momento dramático distinto do toque alegre e vivaz da música para dançar. As diferenças entre os temas, assim como a especificidade de determinadas frases executadas pelo flautero (que se destacam como figuras de um fundo sonoro - leve-se em consideração que tanto temïmbï quanto pinguyo são executados no registro agudo dos instrumentos), têm um papel estruturante na organização do rito. Tanto a repetição sonora quanto as variações que o flautero introduz são aqui responsáveis pela sintonia nos movimentos dos participantes. Portanto, repetição e diferença pautam formalmente as temporalidades que se estruturam por meio do rito ${ }^{17}$.

A relevância das diferenças entre os toques de flautas pode ser constatada no fato de elas induzirem formas de ação particulares entre os participantes, orquestrando os movimentos das pessoas que 
dançam e dos outros personagens que em determinados momentos entram na arena ritual. Sem necessidade de apelar ao discurso verbal, a flauta indica que a roda de dançarinos deve mudar de sentido e "avisa" quando fazer uma pausa na dança; a flauta, ao tocar o tema oguata pegua "avisa" que o conjunto marchará para uma outra casa para continuar dançando lá; a flauta, ao tocar colla-colla homenageia às antigas relações com os colla ${ }^{18}$. É nesses termos que os músicos explicam o significado do tema colla-colla. Segundo um flautero de Santa Teresita, no Paraguai: "[...] al mediodia y a las tres se toca colla-colla en homenaje a los colla porque antiguamente eran nuestros aliados, después se pelearon, y después volvieron a invitarlos a la fiesta." (Quanto há de mito e quanto há de história nesse tipo de explicação é difícil de precisar).

A flauta também anuncia a entrada dos kuchi-kuchi (crianças e jovens que, com o corpo coberto de barro, "vestem-se" de porcos, carregando lama em um saquinho para com ela sujar as pessoas que participam da festa); a flauta "avisa" às mascaritas que o tigre e o touro estão vindo para lutar com elas; a flauta anuncia que está na hora de encerrar o carnaval, se despedir dos aña, chorar da saudade que os mortos provocam e destruir as máscaras (e, caso haja água nas redondezas, tomar uma banho de rio para limpar e afugentar o que os aña possam ter trazido de ruim com eles). As pessoas, de modo geral, e não apenas os flauteros, distinguem os temas que pautam a sequência ritual do arete, o que nos permite reconhecer que existe um repertório e uma organização sequencial historicamente sedimentados na área. Seguindo a proposta de Piedade na sua teorização sobre as tópicas, observa-se que aqui determinadas unidades formais do discurso musical (motivos, frases, temas, padrões rítmicos, etc.),

[...] para além de seu papel funcional nos segmentos formais, muitas vezes apresentam qualidades semióticas a elas atribuídas, ethoï, o que ocorre na maioria das vezes por meio de convenção cultural (diga-se, histórica e tácita). (Piedade, 2013, p. 8)

Por mais que os repertórios interpretados pelos diferentes flauteros nas muitas comunidades chané e guarani da região não sejam idênticos, existem temas que podem ser identificados como standards da música do arete, na medida em que são conhecidos e nomeados da mesma 
maneira, tanto na Bolívia, no Paraguai, quanto na Argentina. Esse é o caso de temas como o "do touro e o tigre" ou "coya-coya". Embora cada flautero os interprete com variantes, relativas ao seu estilo individual de tocar e à flauta que toca, os temas são os mesmos em comunidades separadas por distâncias de até 700 quilômetros ${ }^{19}$.

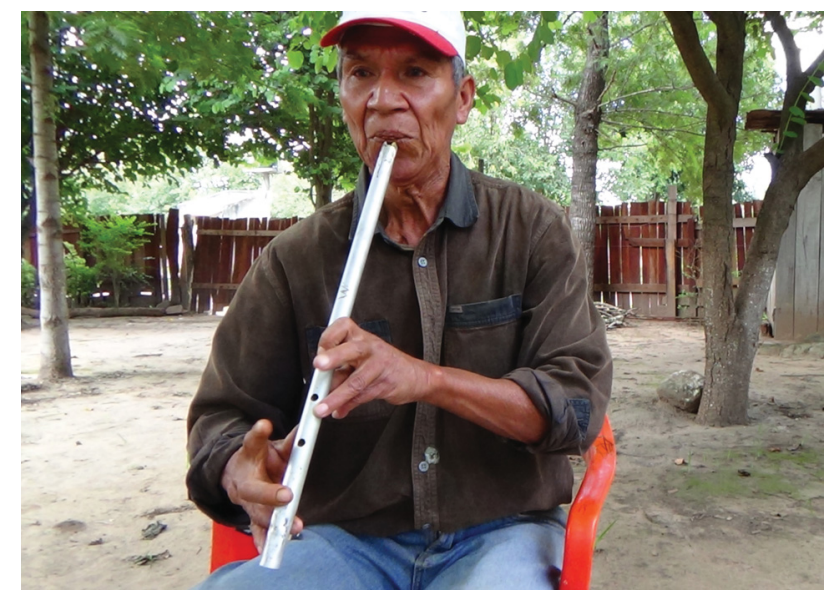

Figura 1: Martín Conti, Tuyunti (Salta, Argentina), fevereiro de 2014 Fonte: Domínguez (2017)

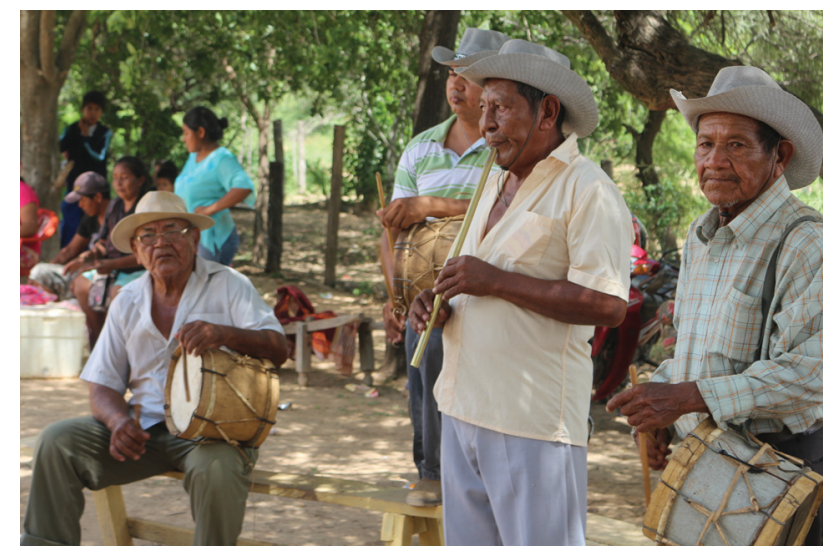

Figura 2: O flautero Pascual Toro junto aos cajeros de Santa Teresita (Paraguai), fevereiro de 2017

Fonte: Domínguez (2017)

A impressão que fica dessa paisagem sonora é que durante o tempo do arete as diferenças são englobadas, em uma relação hierárquica ${ }^{20}$, pela continuidade da tradição musical. Os sons do arete - expressão que 
alguns traduzem como tempo verdadeiro ou hipertempo (Nino [1912] apud Sánchez, 1998, p. 225) - ao opacar as diferenças, marcam o tempo do que permanece, o tempo em que é possível dançar novamente com os que já partiram, o tempo que mantém vivos os vínculos com os parentes que já não estão. Se repetindo a si mesmos em um continuo ritornello, os sons do arete desafiam a finitude, sobretudo, a sua própria finitude. $^{21}$

Com essas observações busquei pensar os sons do arete, considerando suas implicâncias, tanto no tempo do rito quanto no tempo histórico. Para além de quaisquer diferenças - étnicas, linguísticas ou nacionais - comunidades chané e guarani do Chaco ocidental partilham a linguagem musical do arete e alguns dos significados a ela associados. Deslocamentos históricos pelo espaço chaquenho contribuíram para que a música do arete se sedimentasse como uma língua franca ${ }^{22}$, partilhada por populações chané e guarani em uma extensa região. Estruturalmente, pela forma dos toques, quanto estilisticamente considerando-se tanto os instrumentos utilizados, com seus timbres particulares, quanto as características gerais da performance - a música do arete evidencia continuidades nesse amplo espaço. A temática do arete também é a mesma em todos os lugares, por mais que existam diferenças nos mitos que acompanham as performances e nos roteiros que as organizam. A musicalidade do arete é, por tanto, um idioma enraizado na herança histórica da região, que em alguma medida transcende diferenças étnicas, linguísticas e nacionais. As continuidades nos sons do arete são produto da história e, por sua vez, produzem uma história em que a musicalidade indígena define formas particulares de habitar o tempo e o espaço.

\section{Notas}

1 Pessoas que curam (curar aqui é um termo semanticamente mais amplo do que o é no âmbito da biomedicina).

2 Alma, espírito ou imagem dos mortos. Embora em muitas traduções cristãs contemporâneas - penso, por exemplo, nos materiais bíblicos traduzidos pelos Testemunhas de Jeová - o termo é usado como sinônimo de diabo (enquanto ï a é traduzido como alma) a correspondência semântica entre ambos os termos é questionável. $A \tilde{n} a$ e ï a formam um par que remete parcialmente à oposição entre o mal e o bem, evocando também outras oposições, como o contraste entre mortos e vivos. Para uma análise das nuances semânticas desses termos, ver Villar (2008). 
3 Fora esses períodos, eu visitei as comunidades em outros momentos do ano (nos meses de abril, julho-agosto, setembro, outubro) para realizar observações e entrevistas no âmbito do projeto "Arte e Sociabilidades indígenas no Chaco occidental", CNPQ- CHSSA 2015.

4 Para uma descrição detalhada dos instrumentos executados no arete (temïmbï, pinguyo, angúa, angúa guasu e erkencho), remeto a Perez Bugallo (1982).

$5 \mathrm{O}$ "trago" pode ser qualquer bebida alcoólica. Antigamente bebia-se fundamentalmente chicha (bebida de milho fermentado). Hoje também tem chicha nas casas onde se dança, mas além dela, bebe-se outras bebidas alcoólicas fermentadas ou destiladas, principalmente vinho e cerveja, destilado de cana, ou álcool de limpeza diluído em água.

6 Como nos Andes, aqui o calendário agrícola antes da chegada dos missionários cristãos estava associado à saída das plêiades, fenômeno que acontece três semanas antes do solstício de inverno.

7 Embora a presença missionária cristã não se reduza às ordens católicas, pode se afirmar que tanto no extremo oeste do Chaco argentino quanto na região entre Santa Cruz de la Sierra e Yacuíba, em território boliviano, e no oeste do Chaco paraguaio, a ação evangelizadora mais permanente foi encabeçada por missões de cappuccinos, franciscanos e oblatos - estes últimos apenas no Paraguai. Veja Saignes (2007), Sánchez (1998), Pérez Bugallo (2016), Fritz (1999) e Ratzlaff (2009).

8 Matyvirocho pode ser traduzido como lugar longínquo. O termo é utilizado pelos guarani do oeste paraguaio, não sendo reconhecido pelos guarani ou chané de Argentina a quem preguntei. Estes últimos se referem a esse lugar distante como ivoka, termo compreendido e considerado sinônimo do primeiro pelos guarani do Paraguai. Combès identifica o uso do mesmo termo entre os isosenhos, particularmente no período do carnaval e para se referir ao lugar de onde vêm os antepassados (Combès, 2005, p. 75-89).

9 Ouvi os quatro mitos cujos motivos aqui sintetizo nas comunidades de Tuyunti e Campo Durán, na Argentina, e em Santa Teresita e Macharetí, no Paraguai, respetivamente. Em Tuyunti (Argentina) ouvi de um flautero chané que é a raposa quem traz o carnaval de aguararenta (geralmente traduzido na literatura como o lugar/ aldeia dos mortos). Em Campo Durán (Argentina), ouvi de outro homem chané, que sempre morou nessa mesma comunidade, o mesmo mito que Riester (1998) ouviu entre os isosenhos, segundo o qual uma raposa chega à aldeia onde as pessoas tinham preparado chicha e comida para a festa, dizendo que ela era o carnaval; as pessoas - enganadas - a recebem e iniciam a festa da qual ela se aproveita para beber, comer e dançar à vontade.

${ }^{10}$ Existem tabus associados à execução da música do arete fora do marco temporal da festa. Ouvi dizer que existe o perigo de contrair sarna caso o flautero toque no seu temïmbi ou pinguyo a música do arete depois de clausurado o evento.

11 Sobre as formas de escuta inscritas na literatura etnológica americanista de inícios do século XX, remeto a Garcia (2015).

12 Exemplo audiovisual 1. Repetição em forma de progressão descendente com variação. Disponível em: <https://vimeo.com/239344208>.

13 Exemplo audiovisual 2. No som que os passos produzem ao friccionar a terra seca do chão reverbera a estrutura simétrica dos movimentos. Disponível em: <https:// vimeo.com/243538933>.

14 Stanley Tambiah (1985, p. 128), por exemplo, oferece uma definição de ritual em que: "It is constituted of patterned and ordered sequences of words and acts, often 
expressed in multiple media, whose content and arrangement are characterized in a varying degree by formality (conventionality), stereotipy (rigidity), condensation (fusion), and redundancy (repetition)".

15 Devo essa expressão à análise das sequências apresentada por Rafael Menezes Bastos no colóquio "La música y los pueblos indígenas de América", organizado pelo Centro Nacional de Documentación Musical Lauro Ayestarán, de Montevidéu, em setembro de 2015 (inédito).

16 Para análises sobre a centralidade das sequências musicais em um ritual xinguano, remeto a Menezes Bastos (2013); sobre a relação sequência-variação em estudos da música indígena no Brasil, veja Menezes Bastos (2017); sobre a sequencialidade na música popular, veja Seeger (2013); e sobre a dialética com a repetição, Middleton (1983).

17 Percebe-se aqui a mesma dialética que descreve Richard Middleton (1983, p. 244-246) ao tratar das repetições musemáticas e discursivas: "Sequence composes time (rather than marking time or obliterating it, as straight repetition, especially if musematic, seems to do); it makes us aware of rise-and-fall, a discursive hierarchy, and thus refers to irreversible experiences; into the ontology of repetition, it introduces a teleleological directedness".

${ }^{18} \mathrm{O}$ termo coya localmente funciona como genérico que refere as populações andinas, tanto quéchua quanto aymara.

${ }^{19}$ Exemplo audiovisual 3: O touro e o tigre, três versões. A primeira foi registrada na Argentina (flautero: Martín Conti, Tuyunti, fevereiro de 2014), a segunda na Bolívia (flautero de Iyambae, Macharetí, em Aguayrenda, fevereiro de 2015), e a terceira no Paraguai (flautero: Pascual Toro, Santa Teresita, fevereiro de 2017). Disponível em: <https://vimeo.com/249179388>.

${ }^{20}$ No sentido dado à expressão por Louis Dumont (1992) ao falar do englobamento do contrário para pensar as hierarquias estruturais.

${ }^{21}$ Esta interpretação segue a via aberta por Villar e Bossert (2014, p. 12) que analisam o rito do arete em quanto reflexão coletiva sobre o problema da temporalidade: " $E l$ rito funciona como una medida del paso del tiempo y como un espacio de reflexión acerca de la propia mortalidad" (Villar; Bossert, 2014, p. 28).

${ }^{22}$ Inspiro-me aqui na análise que Menezes Bastos (1999) oferece sobre o cerimonial xinguano.

\section{Referências}

ABERCROMBIE, Thomas. Caminos de la memoria en un cosmos colonizado. Poética de la bebida y la conciencia histórica en K'ulta. In: SAIGNES, Thierry (Comp.) Borrachera y memoria: la experiencia de lo sagrado en los Andes. La Paz: Hisbol - IFEA, 1993. p. 139-169.

BEAUDET, Jean-Michel. Souffles d'Amazonie. Nanterre: Société d'Ethnologie, 1997.

BRABEC, Bernd; SEEGER, Anthony. Introduction: Music, Humans and Non-humans. Ethnomusicology Forum, [S.l.], v. 22, n. 3, p. 269-286, 2013. 
COMBÈS, Isabelle. De Sanandita al Itiyuro: los chanés, los chiriguanos (¿y los tapietes?) al sur del Pilcomayo. Indiana, Berlin, v. 24, p. 259-289, 2007.

. Etnohistorias del Isoso: Chané y chiriguanos en el Chaco boliviano (siglos XVI a XX). La Paz: PIEB-IFEA, 2005.

DOMÍNGUEZ, María Eugenia. Western Chaco flutes and flute players revisited. In: LANDA, Cámara; ISOLABELLA, Matías. (Ed.) Audiovisual Ethnomusicology. Sevilha: International Council for Traditional Music (ICTM)/Universidad de Sevilha. 2016. p. 115-132.

DOMÍNGUEZ, María Eugenia. Vimeo: cinco vídeos. 2017. Disponível em: $<$ https://vimeo.com/user53604220>. Acesso em: 5 maio 2018.

DUMONT, Louis. Homo hierachicus: o sistema das castas e suas implicações. São Paulo: Edusp, 1992.

FRITZ, Miguel. Pioneros en el Chaco: misioneiros oblatos del Pilcomayo. Quito: Editorial Abya-Ayala, 1999.

GARCIA, Miguel A. Un oído obediente (y algunas desobediências). In: BRABEC, B.; LEWY, M.; GARCIA, M. A. (Org.). Sudamérica y sus mundo audibles. Estudios Indiana 8. Berlin: Ibero-Americanisches Institut- Gebr. Mann Verlag, 2015. p. 197-210.

GIANNECCHINI, Doroteo. Historia natural, etnografía, geografía, lingüística del Chaco boliviano. Tarija: FIS/Centro Eclesial de Documentación, 1996 [1898].

HILL, Jonathan. Musicalizando o outro. Etnomusicologia na era da globalização. In: MONTARDO, D. L.; M. E. DOMÍNGUEZ (Org.). Arte e sociabilidades em perspectiva antropológica. Florianópolis: Edufsc. 2014. p. 13-46.

LEACH, Edmund. Repensando a antropologia. São Paulo: Perspectiva, 1974.

MAGRASSI, Guillermo. Chiriguano-chané. Buenos Aires: Búsqueda Centro de Artesanía Aborigen, 1981.

MARTINEZ, Rosalía. Tomar para tocar, tocar para tomar. In: SÁNCHEZ, Walter. (Ed.). La música en Bolivia: de la prehistoria a la actualidad. Cochabamba: Fundación Simón I. Patiño. 2002. p. 413-434. . Músicas, movimentos, colores en la fiesta andina. Ejemplos bolivianos. Anthropologica, [S.l.], año XXXII, n. 33, p. 87-110, 2014. MENEZES BASTOS, Rafael J. de. Tradução intersemiótica, sequencialidade e variação nos rituais musicais das terras baixas da América do Sul.

Revista de Antropologia, São Paulo, v. 60, n. 2, p. 342-355, 2017. 
A festa da Jaguatirica: uma partitura crítico-interpretativa. Florianópolis: EDUFSC, 2013.

A Musicológica Kamayurá: para uma Antropologia da Comunicação no Alto Xingu, 2. ed. Florianópolis: Editora da UFSC, 1999.

MIDDLETON, Richard. Play It Again Sam: Some Notes on he Productivity of Repetition in Popular Music. Popular Music, Cambridge University Press, 1983.

NORDENSKIÖLD, Erland. Exploraciones y aventuras en Sudamérica. La Paz: APCOB, [1924] 2001.

La vida de los índios: el Gran Chaco (Sudamérica). La Paz: APCOB, [1912] 2002.

PEREZ BUGALLO, Nahuel. Guaranies católicos entre frailes chiriguanos: un abordaje microhistórico y etnográfico. Suplemento Antropológico, Asunción del Paraguay, v. LI, n. 2, p. 7-125, diciembre, 2016.

PEREZ BUGALLO, Rubén. Estudio etnomusicológico de los chiriguanochané de la Argentina. Cuadernos del Instituto Nacional de Antropologia, Buenos Aires, v. 9, p. 221-268, 1979-1982.

PIEDADE, Acácio T. C. A teoria das tópicas e a musicalidade brasileira: reflexões sobre a retoricidade na música. El oído pensante, [S.l.], v. 1, n. 1, 2013. Disponível em; <http://ppct.caicyt.gov.ar/index.php/ oidopensante>. Acesso em: $1^{\circ}$ out. 2017.

RATZLAFF, Gerhard. Historia, fe y prácticas Menonitas: un enfoque Paraguayo. Asunción: Instituto Bíblico Asunción, 2009.

RIESTER, Jürgen (Ed.). Chiriguano: los pueblos indígenas de las tierras bajas de Bolivia. La Paz: Apcob, 1994.

. Yembosingaro guasu: el gran fumar. Literatura sagrada y profana guarani. Santa Cruz de la Sierra: Apcob, 1998.

ROCCA, Manuel. Los chiriguano chané. América Indígena, [S.l.], v. XXXIII, n. 3, p. 743-756, 1973.

SAHLINS, Marshall. O pessimismo sentimental e a experiência etnográfica: por que a cultura não é um 'objeto' em via de extinção. Mana, Rio de Janeiro, v. 3, n.1, 1997.

SAIGNES, Thierry. Historia del pueblo chiriguano. La Paz: Plural, 2007.

SÁNCHEZ, Walter. La plaza tomada. Proceso histórico y etnogénesis musical entre los chiriguanos de Bolivia. Latin American Music Review, University of Texas, Austin, v. 19, n. 2, p. 218-243, 1998. 
SEEGER, Anthony. Fazendo parte: sequências musicais e bons sentimentos. Anthropologica, PPGA-UFPE, v. 24, n. 2, p. 7-42, 2013.

SUSNIK, Branislava. Chiriguanos I. Dimensiones etnosociales. Asunción del Paraguay: Museo Etnográfico Andrés Barbero, 1968.

TAMBIAH, Stanley. Culture, Thought and Social Action. An Anthropological Perspective. Cambridge: Harvard University Press, 1985.

VILLAR, Diego. Guaranización, traducción y evangelización de las representaciones anímicas chané. Suplemento Antropológico, [S.l.], v. XLIII, 1, p. 339-386, 2008.

. La religión del monte entre los chané. Suplemento

antropológico, Asunción del Paraguay, v. XLVI, n. 1, p. 151-201, 2011.

VILLAR, Diego; BOSSERT, Frederico. Máscaras y muertos entre los chané. Separata, [S.l.], año XIV, n. 19, p. 12-33, diciembre, 2014.

VILLAR, Diego; COMBÈS, Isabelle (Ed.). Introducción: una aproximación comparativa a las tierras bajas bolivianas. Las tierras bajas de Bolivia: miradas históricas y antropológicas. Santa Cruz de la Sierra: El País Museo de Historia, Universidad Autónoma Gabriel René Moreno, 2012, p. 7-31.

Recebido em 09/01/2018

Aceito em 30/04/2018 